\title{
Características dos Pacientes com Leucemia Infantil no Âmbito Hospitalar e a Contribuição da Fisioterapia: um Estudo Retrospectivo
}

doi: https://doi.org/10.32635/2176-9745.RBC.2021v67n1.1177

\author{
Characteristics of Patients with Childhood Leukemia in the Hospital and the Contribution of Physiotherapy: a Retrospective Study \\ Características de los Pacientes con Leucemia Infantil sin Alcance Hospitalario y con la Contribución de la Fisioterapia: \\ un Estudio Retrospectivo
}

\author{
Gabriella Ferreira'; Emanuelle Gouveia dos Santos²; Isabelle Alves Pinto³; Isabelle Riceto4; Vera Lúcia Israel'; Edneia Amancio de \\ Souza Ramos ${ }^{6}$
}

Resumo

Introdução: As leucemias são caracterizadas pela presença de células imaturas na corrente sanguínea, provenientes das células tumorais na medula óssea, que substituem as células sanguíneas saudáveis. Em crianças com leucemia, é possível visualizar alteraçôes fisicomotoras e respiratórias, como fraqueza muscular, fadiga e redução da função pulmonar. A fisioterapia previne as complicações oriundas do câncer, com uma abordagem biopsicossocial prevista na Classificação Internacional de Funcionalidade, Incapacidade e Saúde (CIF). Objetivo: Avaliar as características de crianças com diagnóstico de leucemia, a contribuição da fisioterapia e investigar o uso da CIF. Método: Trata-se de um levantamento descritivo retrospectivo de prontuários de 76 crianças com diagnóstico de leucemia linfoide aguda (LLA) e/ou leucemia mieloide aguda (LMA), em Hospital Terciário de Curitiba, com diagnóstico entre 2015 e 2018. Resultados: A média de idade dos pacientes foi de 6,75 \pm 4,17 anos; 89,5\% (n=68) dos diagnósticos eram LLA, 5,3\% (n=4), LMA e 5,3\% (n=4), de ambas. A maioria, 67,1\% (n=51), residia em Curitiba-PR e Região Metropolitana; 63,2\% (n=48) utilizaram o sistema de saúde pública como meio de acesso ao hospital e 36,8\% (n=28) usaram outros. Dos 76 prontuários analisados, apenas 14,4\% $(\mathrm{n}=11)$ registraram atendimento fisioterapêutico e o modelo biopsicossocial proposto pela CIF esteve ausente. Conclusáo: Apesar da disponibilidade do serviço de fisioterapia no hospital, não foi identificado um padrão de avaliação, diagnóstico e prescrição fisioterapêutica, assim como os principais acometimentos neuropsicomotores de crianças com leucemia. Palavras-chave: Leucemia; Modalidades de Fisioterapia; Classificaçấo Internacional de Funcionalidade, Incapacidade e Saúde; Oncologia; Crianças.

\begin{abstract}
Introduction: Leukemias are characterized by the presence of immature cells in the bloodstream derived from tumor cells in the bone marrow which replace healthy blood cells. It is possible to visualize, in children with leukemia, physical-motor and respiratory changes, such as muscle weakness, fatigue and reduced lung function. Physiotherapy prevents cancer complications, with a biopsychosocial approach provided for in the International Classification of Functioning, Disability and Health (ICF). Objective: Evaluate the characteristics of children diagnosed with leukemia, the contribution of physiotherapy and investigate the use of ICF. Method: Retrospective descriptive survey of the charts of 76 children diagnosed with acute lymphoid leukemia (ALL) and/or acute myeloid leukemia (AML) in a Tertiary Hospital in Curitiba, between 2015 and 2018. Results: The patient's mean age was $6.75 \pm 4.17$ years; $89.5 \%(\mathrm{n}=68)$ of the diagnostics were ALL, 5.3\% (n=4), AML, and 5.3\% (n=4), both. Most of the patients, $67.1 \%(\mathrm{n}=51)$, lived in Curitiba-PR and in the metropolitan region; $63.2 \%(n=48)$ used the public health system to ensure access to the hospital and $36.8 \%(n=28)$ used other ways. Of the 76 medical charts analyzed, only $14.4 \%(n=11)$ registered physical therapy and no record of the use of the biopsychosocial model proposed by the ICF was found. Conclusion: Despite the availability of physiotherapy at the hospital, a standard of assessment, diagnosis and physiotherapy prescription was not identified, as well as the main neuropsychomotor disorders of children with leukemia.

Key words: Leukemia; Physical Therapy Modalities; International Classification of Functioning, Disability and Health; Medical Oncology; Child.
\end{abstract}

\section{Resumen}

Introducción: Las leucemias se caracterizan por la presencia de células inmaduras en el torrente sanguíneo, derivadas de células tumorales en la médula ósea que reemplazan a las células sanguíneas sanas. En niños con leucemia, es posible ver cambios físicos y motores, como debilidad muscular, fatiga y función pulmonar reducida. La fisioterapia previene las complicaciones del cáncer, con un enfoque biopsicosocial previsto en la Clasificación Internacional del Funcionamiento, Discapacidad y Salud (CIF). Objetivo: Evaluar las características de los nińos diagnosticados con leucemia, cómo la fisioterapia contribuyó e investigar el uso de la CIF. Método: Esta es una encuesta descriptiva retrospectiva de los registros médicos de 76 niños diagnosticados con leucemia linfoide aguda (LLA) y/o leucemia mieloide aguda (LMA) en un hospital terciario en Curitiba, con diagnóstico entre 2015 y 2018. Resultados: La media de la edad de los pacientes fue de 6,75 $\pm 4,17$ años; El 89,5\% ( $\mathrm{n}=68)$ de los diagnósticos fueron ALL, 5,3\% (n=4), AML y 5,3\% ( $n=4)$ de ambos. La mayoría, 67,1\% ( $\mathrm{n}=51$ ) vivía en Curitiba-PR y en la Región Metropolitana; El 63,2\% (n=48) utilizó el sistema de salud pública como medio de acceso al Hospital y el 36,8\% ( $\mathrm{n}=28)$ utilizó otros. De los 76 registros médicos analizados, solo el $14,4 \%(n=11)$ registró fisioterapia y el modelo biopsicosocial propuesto por la CIF estaba ausente. Conclusión: A pesar de la disponibilidad del servicio de fisioterapia en el hospital, no se identificó un estándar de evaluación, diagnóstico y prescripción de fisioterapia, así como los principales trastornos neuropsicomotores de los nin̄os con leucemia.

Palabras clave: Leucemia; Modalidades de Fisioterapia; Clasificación Internacional del Funcionamiento, de la Discapacidad y de la Salud; Oncología Médica; Niño.

\footnotetext{
1-6Universidade Federal do Paraná (UFPR). Curitiba (PR), Brasil.

${ }^{1}$ Curso de Fisioterapia. E-mail: gabrielllaferreira13@gmail.com. Orcid iD: https://orcid.org/0000-0003-3302-1775

${ }^{2}$ Curso de Fisioterapia. E-mail: emanuellegouveia.s@gmail.com. Orcid iD: https://orcid.org/0000-0003-1490-6404

${ }^{3}$ Curso de Fisioterapia. E-mail: isabellea2662@gmail.com. Orcid iD: https://orcid.org/0000-0003-1006-7869

${ }^{4}$ Curso de Fisioterapia. E-mail: ricetoisabelle@gmail.com. Orcid iD: https://orcid.org/0000-0002-5895-0557

${ }^{5}$ Departamento de Prevenção e Reabilitação em Fisioterapia e Programa de Pós-Graduação em Educação Física. E-mail: vera.israel@ufpr.br. Orcid iD: https:// orcid.org/0000-0001-5824-7792

${ }^{6}$ Programa de Pós-Graduação em Microbiologia, Parasitologia e Patologia. E-mail: edneiaama@ufpr.br. Orcid iD: https://orcid.org/0000-0002-8855-5988

Endereço para correspondência: Edneia Amancio de Souza Ramos. Avenida Coronel Francisco Heráclito dos Santos, s/n - Centro Politécnico. Curitiba (PR), Brasil. CEP 81531-980. E-mail: edneiaama@ufpr.br
} 


\section{INTRODUÇÃO}

A leucemia é uma doença maligna do sistema hematopoiético que surge por alterações genéticas e epigenéticas de uma célula leucocitária progenitora na medula óssea ${ }^{1}$. A partir de uma seleção clonal dessas células alteradas, há redução na produção e interferência na maturação dos glóbulos brancos. A leucemia pode ser dividida em aguda e crônica e, em segundo plano, em linfocítica e mielocítica, dependendo do tipo de célula predominantemente alterada ${ }^{2}$. Na leucemia aguda, os blastos se mostram alterados e, com isso, perdem a sua capacidade de maturação. Em geral, as leucemias agudas são mais agressivas pela sua alta capacidade replicativa, já as crônicas são desencadeadas por alterações de células maduras que contribuem para a sua má funcionalidade, sendo que, em geral, são mais lentas do que as leucemias agudas. Nas leucemias linfocíticas, o tipo de células afetadas são os linfócitos, com formas linfoides ou tecido linfático; enquanto, nas mielocíticas, são as de origem mieloide, como as células brancas não linfocíticas, vermelhas e megacariocíticas ${ }^{2,3}$. Tipos mistos também podem ser encontrados, o que torna complexo o diagnóstico e o tratamento ${ }^{4}$.

As leucemias correspondem ao tipo de câncer mais comum na fase infantojuvenil. Segundo dados do Instituto Nacional de Câncer José Alencar Gomes da Silva $(\text { INCA })^{5}$, as estimativas de incidência, para cada ano do triênio 2020-2022, são de 5.920 casos novos de leucemia em homens e $4.890 \mathrm{em}$ mulheres, correspondendo a um risco estimado de 5,67 casos novos a cada $100 \mathrm{mil}$ homens e 4,56 casos novos a cada 100 mil mulheres. $\mathrm{Na}$ infância, as leucemias correspondem a $33 \%$ de todas as doenças malignas que os acometem até os 14 anos, sendo, portanto, a doença mais comum no mundo ${ }^{6}$. De $30 \%$ a $40 \%$ das crianças e adolescentes diagnosticados entre 0 a 18 anos, a possibilidade de repercussóes futuras no seu desenvolvimento neuropsicomotor é ainda maior, necessitando de acompanhamento multidisciplinar durante longos períodos ${ }^{7,8}$.

O diagnóstico prévio da doença ocorre pelo hemograma e, posteriormente, pela imunofenotipagem, em que é possível distinguir as células por seus marcadores celulares e classificar as leucemias dentro dos seus graus. Na leucemia linfoide aguda (LLA), por exemplo, a imunofenotipagem determina se as alteraçôes se encontram nas linhagens de linfócitos B ou T, de acordo com os traços imunofenotípicos dos linfoblastos ${ }^{9,10}$.

Considerado o tratamento mais comum, a quimioterapia atua sobre as células malignas e sadias do organismo e leva a sintomas como anemia, fadiga, leucopenia, apatia, náuseas, vômitos, alopecia, diarreia, perda de peso, entre outros. Assim como esse tipo de tratamento leva a complicaçóes neuromusculoesqueléticas, como a fraqueza muscular, miopatias, osteoporose, fraturas e osteonecrose, diminuindo os níveis da aptidão física e a densidade mineral óssea da criança. Em geral, os processos terapêuticos na leucemia podem causar desconforto, estresse e internaçóes prolongadas ${ }^{11}$.

Já no processo da fisioterapia oncológica, os objetivos terapêutico-funcionais envolvem preservar, manter e restaurar a integridade cinético funcional dos órgáos e sistemas do paciente, e prevenir os diversos distúrbios causados pelo tratamento da doença ${ }^{12,13}$. Os pacientes infantojuvenis com leucemia podem apresentar atrofia muscular de desuso, alteraçáo da coordenação motora, do equilíbrio corporal, da força muscular e da amplitude de movimento; isso tudo, associado ao repouso prolongado, pode promover alteraçôes respiratórias e vasculares. $\mathrm{Na}$ evolução da doença, a criança pode também sofrer com a diminuição da atuação da força da gravidade nos ossos e tecidos, podendo levar à hipotensáo postural grave.

É essencial que o fisioterapeuta hospitalar avalie, utilize e prescreva o uso, por exemplo, da cinesioterapia motora e pulmonar com objetivos terapêuticos e funcionais, para adequar os posicionamentos de pacientes acamados, variando as posiçóes e posturas no ambiente hospitalar, chegando ao ortostatismo, quando possível, de modo ativo e funcional. Bem como, para exercícios fisioterapêuticos de resistência e fortalecimento muscular, treino de propriocepção, restauração da amplitude de movimento articular e prevençáo de fadiga ${ }^{14}$, de modo adequado e lúdico para a realidade da criança - que é o paciente, neste caso, da leucemia.

No caso da fisioterapia pediátrica em oncologia, a abordagem biopsicossocial, que traz a funcionalidade como indicador de saúde ${ }^{15}$ e um olhar ampliado de atenção à saúde da criança, considera aspectos funcionais da condição de saúde, das dimensôes de função e estrutura como condiçáo da mobilidade de cada paciente, presença de dor ou desconforto, entre outros aspectos que dependerão da avaliação fisioterapêutica.

Também nas dimensóes de atividades e participação da Classificação Internacional de Funcionalidade, Incapacidade e Saúde (CIF) ${ }^{16}$, da Organização Mundial da Saúde (OMS), considerando, dentro do processo fisioterapêutico na oncologia, as capacidades e o desempenho da criança com leucemia na diversidade de tarefas cotidianas, de brincar, terapias específicas, entre outras, e o seu grau de envolvimento na adesão do tratamento. Além dos fatores ambientais e pessoais específicos de cada criança, que contribuem para o desenvolvimento, e, por fim, contemplando o objetivo de oferecer uma linguagem unificada e padronizada para descrição de estados relacionados à saúde ${ }^{16,17}$.

Ademais, nos aspectos contextuais da CIF, os fatores ambientais e pessoais envolvem também o desenvolvimento neuropsicomotor da criança com leucemia. A família 
envolvida no cuidado pode ser facilitadora nesse ambiente familiar ou ainda na questáo escolar e de lazer, com brincadeiras adequadas à cada faixa etária, o que auxiliaria na recuperaçáo da criança que, para tanto, precisa da orientação da fisioterapia para promoção e educação em saúde. Os fatores pessoais específicos de cada criança contribuem para o seu desenvolvimento e dependem da sua história psicomotora, da estimulação, do envolvimento nutricional e da presença de outras comorbidades. Assim, com esse olhar ampliado biopsicossocial em saúde, é possível prescrever adequadamente o tratamento fisioterapêutico para leucemia na infância, promovendo a saúde e evitando suas complicaçóes, podendo-se utilizar da CIF para acompanhar esse processo de evoluçáo da criança. A CIF tem como objetivo oferecer uma linguagem unificada e padronizada para descriçáo de estados relacionados à saúde, por meio de códigos que facilitam a coleta e o registro dos dados das crianças, como no caso deste estudo. Assim, após a avaliação fisioterapêutica, pôde-se indicar categorias e qualificadores da condiçáo de saúde nos domínios de Funções (b); Estruturas do Corpo (s); Atividades e Participação (d); Fatores Ambientais; (e) Fatores Pessoais. Desse modo, em cada fase de recuperaçáo na evoluçáo da criança com leucemia, devem ser considerados aspectos da queixa principal, facilitando mapear e adequar a intervenção fisioterapêutica e multiprofissional na oncologia pediátrica ${ }^{16,17}$.

Nessa perspectiva, este estudo tem como objetivo analisar as características dos pacientes internados no hospital com diagnóstico de leucemia infantil, identificando, por meio dos prontuários clínicos, as intervençôes fisioterapêuticas realizadas nas crianças e investigar o uso do modelo biopsicossocial da CIF, caracterizado em diferentes dimensōes de funcionalidade e contextos da doença.

\section{MÉTODO}

Trata-se de um estudo descritivo retrospectivo ${ }^{18}$ cujos critérios de inclusão considerados foram: indivíduos com diagnóstico de LLA e/ou leucemia mieloide aguda (LMA), utilizando os códigos CID-10 - C91.0 e CID-10 - C92.0, respectivamente; idade entre 0 a 15 anos; atendidos pelo Hospital Terciário de Curitiba-PR, entre os períodos de 2015 a 2018. Já os critérios de exclusão foram: indivíduos com idade superior a 15 anos, com tempo de atendimento hospitalar menor que 24 horas, atendidos pelo hospital fora do período de 2015 a 2018. A partir dos códigos CID-10 - C91.0 e CID-10 - C92.0, foram selecionados 150 prontuários do livro de admissão do Serviço de Oncologia e passados ao Sistema de Arquivos Médicos e Estatísticos (SAME) conforme rotina hospitalar. Destes, apenas 76 atenderam aos critérios de inclusão: indivíduos com diagnóstico de LLA e/ou LMA; idade entre 0 a 15 anos; atendidos no Hospital Terciário de Curitiba-PR, entre o período de 2015 a 2018.

Os dados coletados foram selecionados de prontuários do livro de admissão do Serviço de Oncologia e passados ao SAME e registrados de modo que se garantissem o sigilo e a privacidade dos pacientes. As seguintes informaçōes foram obtidas dos prontuários para as análises: data de nascimento, gênero, data do diagnóstico, diagnóstico clínico, cidade, meio de acesso ao hospital (convênio, particular ou sistema de saúde pública), anamnese, tipo sanguíneo, dados de transfusão sanguínea, exames complementares, doenças concomitantes, complicaçôes pós-tratamento neoplásico, acompanhamento e tratamento fisioterapêutico. Identificaram-se as categorias principais considerando os domínios da abordagem biopsicossocial da CIF.

O estudo foi aprovado pelo Comitê de Ética em Pesquisa envolvendo seres humanos da Associação Hospitalar de Proteção à Infância Dr. Raul Carneiro, sob o número CAAE 80584817.5.0000.0097.

\section{RESULTADOS}

Foram selecionados 150 prontuários; destes, apenas 76 atenderam aos critérios de inclusão. Dos 76 prontuários analisados, a média de idade dos pacientes foi de $6,75 \pm 4,17$ anos, sendo que $89,5 \%(\mathrm{n}=68)$ tinham o diagnóstico de LLA; 5,3\% (n=4) LMA; e 5,3\% (n=4) diagnóstico clínico para ambas as neoplasias. Do total, $43,4 \%(n=33)$ eram do gênero feminino e $56,6 \%(n=43)$ do gênero masculino.

Do total de crianças atendidas pelo Hospital, 67,1\% ( $\mathrm{n}=51)$ residiam em Curitiba-PR e Regiāo Metropolitana, e $32,9 \% \quad(n=25)$ vieram de outras cidades para o tratamento. $\mathrm{O}$ meio de acesso ao hospital pelo sistema de saúde pública foi de $63,2 \%$ (n=48), enquanto $36,8 \%$ $(\mathrm{n}=28)$ por outros convênios e particulares (Figura 1).

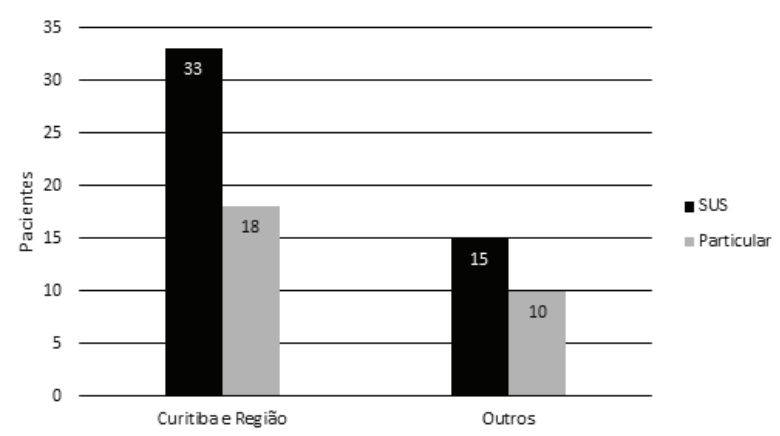

Figura 1. Meio de acesso ao hospital e origem dos pacientes: dados relacionados ao local de habitação e tipo de convênio utilizado 
$\mathrm{Na}$ anamnese descrita nos prontuários, fatores como febre $(31,6 \%)$ e equimoses $(13,2 \%)$ foram os mais predominantes nos relatos, enquanto vômitos e náuseas $(11,8 \%)$, perda de peso $(9,2 \%)$ e diarreia $(5,3 \%)$ foram encontrados em menores proporçóes (Tabela 1). O sintoma prevalente após início do tratamento foi a neutropenia febril em $23,7 \%$ dos pacientes, também associada a outras condiçôes sintomatológicas, tais como anemia, e 1,3\% apresentou pancitopenia. Entre a distribuição dos grupos sanguíneos, os mais prevalentes foram os tipos O $(39,5 \%)$ e A $(31,6 \%)$, e o fator Rh positivo prevaleceu (73,7\%); destes, $72,4 \%$ realizaram transfusão sanguínea em algum momento do tratamento.

Quanto ao tratamento fisioterapêutico, apenas 11 pacientes $(14,4 \%)$ tinham algum registro no prontuário do procedimento realizado, sendo $7,9 \%$ a fisioterapia respiratória, 2,6\% a fisioterapia motora e 3,9\% ambas as intervençóes. Se ainda a amostra for estratificada em relaçáo ao tipo de convênio, observa-se que apenas 12,5\% dos pacientes do sistema de saúde pública receberam alguma intervenção da fisioterapia, enquanto 17,9\% dos pacientes internados pelo convênio e/ou particular receberam o tratamento da fisioterapia (Figura 2).

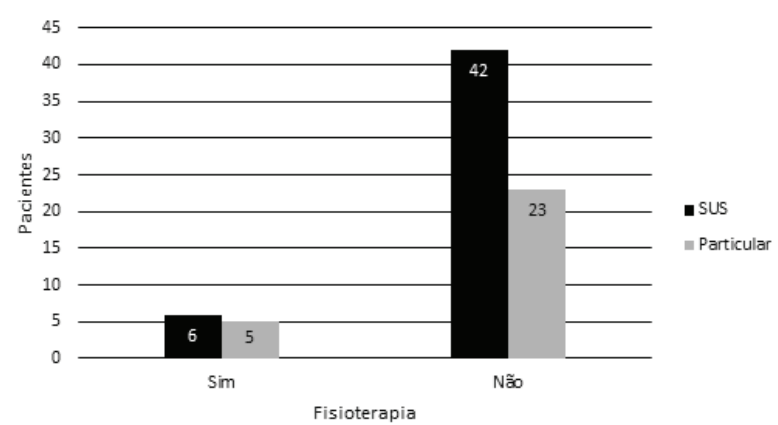

Figura 2. Relação entre fisioterapia e convênio: dados sobre a quantidade de atendimentos fisioterapêuticos encontrados nos prontuários e sua correlação com o convênio de saúde

$\mathrm{Na}$ análise dos prontuários, que continham anotaçóes do atendimento fisioterapêutico realizado, não foram encontradas informaçôes específicas desses atendimentos,

Tabela 1. Características dos pacientes

\begin{tabular}{|c|c|c|c|c|c|}
\hline \multicolumn{2}{|c|}{ Item do prontuário } & Subdivisão & $\mathbf{n}$ & $\%$ & Sem informações \\
\hline \multirow{5}{*}{\multicolumn{2}{|c|}{ Anamnese }} & Febre & 24 & 31,6 & \multirow{5}{*}{$57,9 \%(n=44)$} \\
\hline & & Diarreia & 4 & 5,3 & \\
\hline & & Perda de peso & 7 & 9,2 & \\
\hline & & Equimose & 10 & 13,2 & \\
\hline & & Vômito/náuseas & 9 & 11,8 & \\
\hline \multirow{2}{*}{\multicolumn{2}{|c|}{ Presença de outras neoplasias }} & $\operatorname{Sim}$ & 9 & 11,8 & \\
\hline & & Não & 67 & 88,2 & \\
\hline \multirow{3}{*}{$\begin{array}{l}\text { Complicações } \\
\text { pós-quimioterapia }\end{array}$} & \multirow[t]{2}{*}{ Sim } & $\begin{array}{c}\text { Neutropenia febril e/ou } \\
\text { anemia }\end{array}$ & 18 & 23,7 & \\
\hline & & Pancitopenia & 1 & 1,3 & \\
\hline & Não & & 57 & 75 & \\
\hline \multirow{6}{*}{\multicolumn{2}{|c|}{ Tipo sanguíneo }} & O & 30 & 39,5 & \multirow{6}{*}{$19,7 \%(n=15)$} \\
\hline & & A & 24 & 31,6 & \\
\hline & & B & 5 & 6,6 & \\
\hline & & $A B$ & 2 & 2,6 & \\
\hline & & Positivo & 56 & 73,7 & \\
\hline & & Negativo & 5 & 6,6 & \\
\hline \multirow{2}{*}{\multicolumn{2}{|c|}{ Transfusão }} & Realizado & 55 & 72,4 & \\
\hline & & Não realizado & 21 & 27,6 & \\
\hline \multirow{3}{*}{\multicolumn{2}{|c|}{ Tratamento fisioterapêutico }} & Respiratório & 6 & 7,9 & \multirow{3}{*}{$85,5 \%(n=65)$} \\
\hline & & Motor & 2 & 2,6 & \\
\hline & & Ambos & 3 & 3,9 & \\
\hline \multicolumn{2}{|l|}{ Óbito } & & 6 & 7,9 & \\
\hline
\end{tabular}


sem a presença de uma ficha com dados da avaliação fisioterapêutica e das técnicas de tratamento adotadas pelos profissionais.

Foi possível observar que o modelo biopsicossocial proposto pela CIF não consta nos prontuários, sendo questionável a sua utilização pelos fisioterapeutas e outros profissionais da saúde do Hospital Terciário. Com base na revisão de literatura, o modelo Biopsicossocial de Funcionalidade e Saúde da CIF foi esquematizado no diagrama (Figura 3) de interação entre os domínios da condição de saúde, funcionalidade (funções, estruturas, atividades e participação) e contextos (ambientais e pessoais) envolvendo as características principais dos pacientes com leucemia ${ }^{16}$.

\section{DISCUSSÃO}

A delimitação metodológica do tipo retrospectivo do estudo foi utilizada para analisar as características clínicas dos pacientes que foram internados no hospital ${ }^{18}$. Propostas como esta auxiliam a estabelecer diretrizes para que novas abordagens terapêuticas, estudos prospectivos e de ensaio controlado sejam realizados. Visto isso, o presente estudo indica, conforme a literatura relata, que a leucemia e o tratamento oncológico podem gerar algumas limitaçóes cinético-funcionais, sendo papel da fisioterapia diagnosticar tais limitaçóes e recuperar a integridade, embora não tenham sido relatadas as limitaçóes nos prontuários, apenas assinalada a necessidade

\section{CONDIÇÃO DE SAÚDE}

Pacientes atendidos em Hospital Terciário de Curitiba-PR, entre os anos de 2014-2017, com diagnóstico de leucemia linfoide aguda (CID-10 - C91.0) e/ou mieloide aguda (CID-10 - C92.0), apresentando como sinais e sintomas predominantes: febre, diarreia, perda de peso, equimoses, náuseas e/ou vômitos

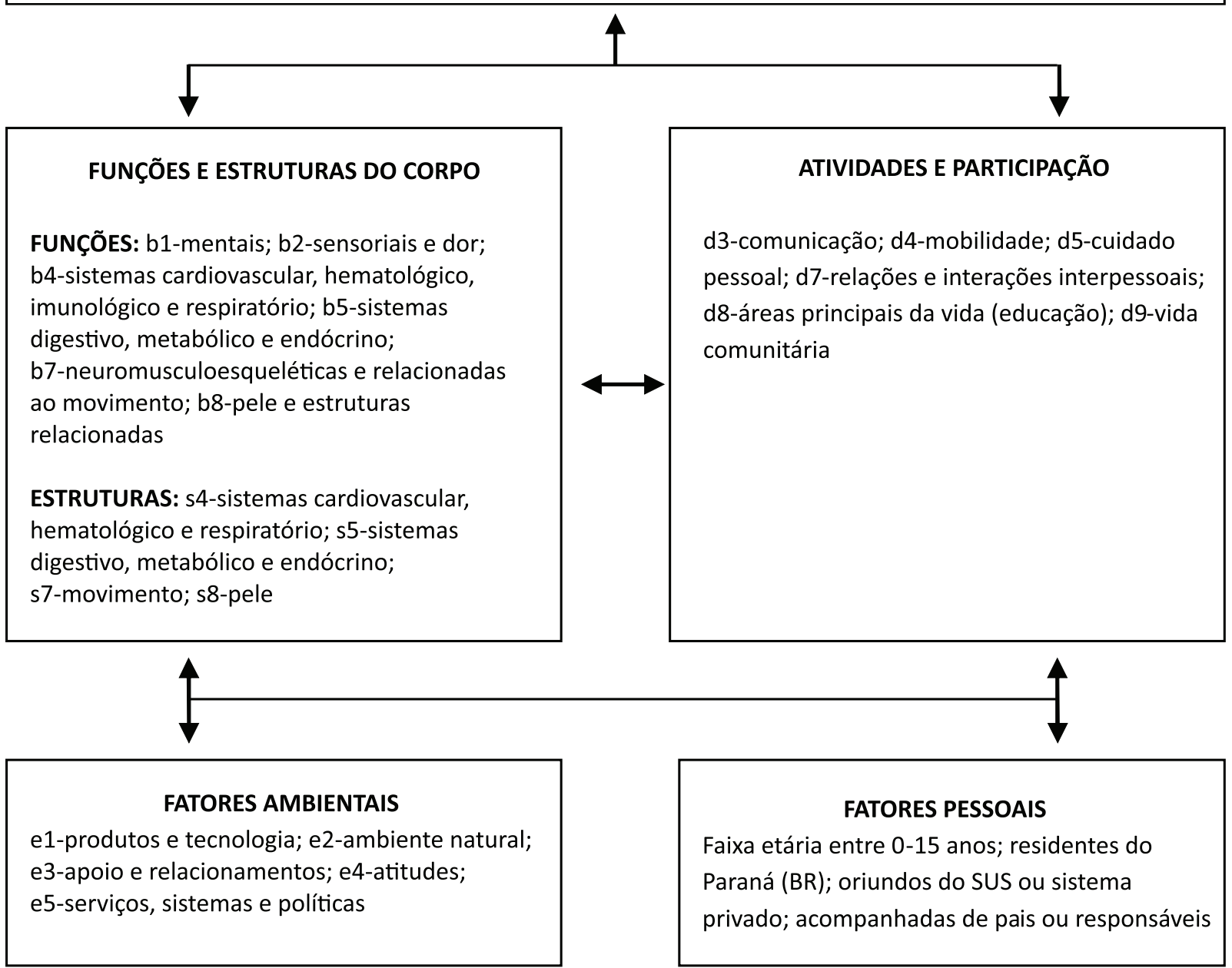

Figura 3. Proposta de organização do modelo biopsicossocial da CIF: diagrama de interação entre domínios de condição de saúde, funcionalidade (funções, estruturas, atividades e participação) e fatores contextuais (ambientais e pessoais) dos casos analisados 
da intervenção fisioterapêutica. Foi recomendada ainda a realização de sessôes diariamente, de forma humanizada, após avaliação fisioterapêutica minuciosa em pacientes oncológicos ${ }^{13,19}$.

Neste trabalho, observou-se prevalência de 89,5\% dos pacientes com diagnóstico de LLA, resultado que corrobora os dados estimados pelo INCA ${ }^{5}$, cuja neoplasia infantil é a mais frequente ${ }^{5}$.

$\mathrm{Na}$ anamnese, o presente estudo confirma os achados de Oliveira ${ }^{20}$, que indicou febre, equimose, perda de peso, náuseas e vômitos como os sintomas iniciais de pacientes com leucemia aguda, mas difere em relação aos achados mais prevalentes, tais como dor e astenia, não avaliados ou não relatados nos prontuários. Segundo Torres ${ }^{21}$, a ocorrência de febre associada à neutropenia é relatada em até $80 \%$ dos pacientes nas neoplasias hematológicas após pelo menos um ciclo de quimioterapia, dado que não reforça o presente estudo. Apesar de ser o sintoma prevalente, a neutropenia febril foi apresentada por apenas $23,7 \%$ dos pacientes.

Os resultados também vão ao encontro dos achados de Souza et al. $^{22}$, que, por meio do levantamento de diagnósticos de câncer em 30 pacientes pediátricos, encontraram incidência maior foi de LLA. Da mesma forma, o estudo de Beloto ${ }^{23}$ indica que a incidência anual de LLA é o dobro da taxa de LMA e que ambas ocorrem em maior número no sexo feminino do que no sexo masculino. Um dado relevante também obtido é que a taxa de óbito na população avaliada foi de apenas 7,9\%.

Considerando o local de habitação, observou-se que $32,9 \%$ dos pacientes residiam em outras cidades (Figura 1) e precisavam viajar para conseguir tratamento oncológico. Assim como relatado no estudo de Teston et al. ${ }^{24}$, no qual procuraram compreender os sentimentos e as dificuldades vivenciadas por pacientes oncológicos frente aos itinerários de diagnóstico e terapêuticos, a necessidade de se deslocar para outro município impacta diretamente no tratamento, pois causa cansaço em virtude da viagem, influenciando no bem-estar e na qualidade de vida do paciente.

Observou-se na presente pesquisa o predomínio de pacientes com Rh Positivo (Tabela 1), estando de acordo com determinados estudos ${ }^{25,26}$, que analisaram a prevalência de grupos sanguíneos na população brasileira e constataram o Rh positivo como o mais frequente, de acordo também com dados da Santa Casa de São Paulo ${ }^{27}$, que afirma que $80,5 \%$ da população possuem Rh Positivo e apenas 19,5\% Rh Negativo, fator este que facilita na busca de possíveis doadores de sangue e medula compatíveis.

Há o predomínio de pacientes amparados pelo sistema de saúde pública frente ao tratamento de leucemias no hospital em relação aos convênios particulares (Figura 1), o que pode ser amparado pelo alto custo dos procedimentos destinados aos pacientes oncológicos. O sistema de gestão dos hospitais públicos, realizado pela Empresa Brasileira de Serviço Hospitalares (EBSERH) ${ }^{28}$, em seu guia de Procedimentos Operacional Padrão: Fisioterapia em Oncologia Pediátrica, preconiza a utilização das mesmas técnicas e recursos no tratamento de pacientes pediátricos oncológicos dos demais, diferenciando-se a percepção do seu estado geral em razão das particularidades inerentes ao tratamento submetido.

Embora o número de encaminhamentos e atendimentos fisioterapêuticos identificados nos prontuários médicos dos pacientes analisados tenha sido baixo, a fisioterapia é uma aliada no tratamento oncológico de crianças. Estudos como o de Marchese et al. ${ }^{29}$ comprovam que, após a intervenção fisioterapêutica, durante cinco sessôes associadas a instruçôes de exercícios domiciliares individualizados, pode haver melhora nas funçóes da marcha e da qualidade de vida de crianças com LLA $^{29}$; assim como no estudo de Almeida et al..$^{30}$, que verificou que o exercício físico supervisionado por um fisioterapeuta proporciona redução da fadiga, melhora na qualidade de vida e no condicionamento cardiorrespiratório ${ }^{30}$.

Apesar da escassez de informaçóes obtidas nesta pesquisa a respeito das técnicas fisioterapêuticas adotadas nos atendimentos (Tabela 1), a intervençâo de cinesioterapia/ motora é utilizada a partir de movimentos voluntários, proporcionando mobilidade, flexibilidade, coordenação motora, aumento da força muscular e resistência à fadiga ${ }^{31}$, aplicada aos pacientes, corroborando o estudo de Cruz et $\mathrm{al}^{32}$, que asseguram que deve-se evitar a imobilidade, fator significativo para danos na funcionalidade da musculatura; com isso, houve uma diminuição diária de força muscular de $1,3 \%$ a $3 \%$ e, em uma semana de inatividade, uma reduçáo de $10 \%{ }^{32}$.

Outra intervenção, a mais descrita nos prontuários, foi a fisioterapia respiratória (Tabela 1), que reforça o estudo de Moraes et al..$^{33}$, podendo o seu uso ser justificado, uma vez que os pacientes demonstraram maior redução da função pulmonar e da força muscular respiratória, necessitando da terapia em questão. Igualmente, no levantamento realizado por Freitas et al. ${ }^{31}$, que colocam os exercícios respiratórios como uma das principais manobras fisioterapêuticas em disfunçôes pulmonares como atelectasias, dispneia e secreção.

Durante as sessões, a fisioterapia pode utilizar o lúdico com o intuito de proporcionar um ambiente mais humanizado, oferecendo uma abordagem biopsicossocial às crianças, podendo estar presente na avaliação e no tratamento por meio de diversos materiais e equipamentos, como bola, espelho, esteira, somando-se ainda a brincadeiras e a jogos, tornando a sessão mais 
atrativa ${ }^{34}$. Atualmente, a utilização de jogos de videogame, ou da gameterapia, tem se apresentado como um auxílio no tratamento da reabilitaçáo da habilidade motora, participando do desenvolvimento cognitivo por causa do feedback visual e auditivo ${ }^{35}$. E mesmo encontrando benefícios no uso da fisioterapia em pacientes oncológicos, o estudo de Burdos ${ }^{36}$ conclui que há falta de investimento público para a implementação desses profissionais no ambiente hospitalar para atendimento oncológico ${ }^{36} \mathrm{e}$ escassez de publicaçóes científicas com evidência clínica que comprovem os impactos ${ }^{19}$.

Os dados coletados, contudo, podem não representar a totalidade do atendimento prestado pela unidade investigada, isso porque, apesar de o registro documental ser um instrumento valioso para o fisioterapeuta, conforme regulamentado pelo Conselho Federal de Fisioterapia e Terapia Ocupacional (COFFITO) ${ }^{37,38}$, alguns dados podem ter sido subtraídos das evoluçôes fisioterapêuticas, como no estudo de Teixeira et al. ${ }^{39}$. Além do encaminhamento realizado pelo profissional médico, a manipulaçáo dos registros, feita por diversos profissionais da equipe de atendimento e administrativo que precisam ter acesso aos documentos, ocasiona extravios ao longo dos percursos. Os resultados do estudo de Teixeira et al. ${ }^{39}$ demonstraram que muitos itens eram subtraídos e deveriam constar nas evoluçôes fisioterapêuticas, tornando a fisioterapia insuficientemente representada nos prontuários, sendo o registro documental um instrumento valioso para o fisioterapeuta, conforme regulamentado pelo COFFITO ${ }^{37,38}$.

Com o intuito de estruturar uma descrição em saúde e os estados relacionados a ela, o modelo biopsicossocial proposto pela CIF pode ser um aliado na elaboraçáo de uma intervenção fisioterapêutica envolvendo exercícios que influenciam tanto nas estruturas e funcionalidade corporal, quanto nas adequaçóes e otimizaçóes ambientais, compreendendo o indivíduo em sua totalidade ${ }^{16,40}$. Contudo, a falta de dados encontrados sobre a CIF, assim como no estudo de Ruaro et al. ${ }^{41}$, reafirma que a relevância clínica pode ser considerada baixa e o potencial de implementação fraco ${ }^{41}$, embora o crescimento da CIF seja alto e de grande utilidade para os setores público e privado, fazendo relação entre saúde, funcionalidade e ambiente ${ }^{16}$.

Definidos como um conjunto ou itens principais que representam uma seleção de categorias da CIF, os core sets discorrem sobre características de indivíduos com determinada condição de saúde ${ }^{42}$. Não foram localizados core sets da CIF para pacientes com câncer na literatura, o que poderia explicar a falta de dados e a dificuldade de implementação na área, uma vez que listas específicas e resumidas, como checklist, facilitam a aplicação da CIF pela equipe multidisciplinar de saúde ${ }^{42,43}$. Os fisioterapeutas desenvolvem e selecionam aspectos funcionais da saúde da criança, podendo aplicar esses dados no fluxograma proposto pela CIF, explorando as associaçóes entre eles de forma empírica e ampliando a visão do cuidado ${ }^{17}$.

\section{CONCLUSÃO}

Pode-se afirmar que a fisioterapia é fundamental em pacientes pediátricos com leucemia, porém notou-se uma escassez de informaçóes e um padrão para a descrição dos atendimentos realizados, assim destaca-se a importância de um registro adequado. $\mathrm{O}$ estudo observou uma prevalência de LLA em relação aos pacientes com LMA e, entre os sintomas apresentados, a neutropenia febril foi o mais desenvolvido nos pacientes pós-quimioterapia. Também, embora o local tenha uma boa proposta de infraestrutura do setor de fisioterapia, náo foram encontrados dados nos registros autorizados acessados sobre procedimentos padróes para atendimento de pacientes oncológicos e os registros de encaminhamentos médicos para a fisioterapia mostrou-se baixo. A acessibilidade às informaçóes pode ter sido um fator que contribuiu para o reduzido número de casos observados no presente trabalho, entretanto, os objetivos foram contemplados.

Com intuito de aprimorar e/ou facilitar esse processo, propóe-se a implementação de um prontuário fisioterapêutico e/ou ficha padrão, incluindo categorias funcionais baseadas na abordagem biopsicossocial da CIF, para que, após a realização das avaliaçóes fisioterapêuticas, as informaçóes da avaliação e tratamento fisioterapêutico sejam registradas sempre após o atendimento na evolução de cada paciente, auxiliando no acompanhamento da efetividade da intervençáo fisioterapêutica proposta, facilitando futuras adequaçóes e inovaçóes na área da fisioterapia. Isto possibilitaria uma atuaçáo dos profissionais fisioterapeutas, baseada na tríade experiência, objetivo do paciente/família e da evidência científica, que trará um amparo legal.

Por fim, sugere-se a utilização da CIF como uma ferramenta de estatística, pesquisa clínica, política social e pedagógica, ampliando o uso dessa classificação com medidas simples, tais como treinamentos de profissionais e acadêmicos, e a implementação do uso da codificação da CIF nos sistemas de saúde, além de estudos utilizando core sets da CIF para pacientes com leucemia, facilitando a utilização na prática clínica.

\section{CONTRIBUIÇÕES}

Todos os autores contribuíram na concepção e/ ou no planejamento do estudo; na obtenção, análise e 
interpretação dos dados; assim como na redação e revisão crítica; e aprovaram a versão final a ser publicada.

\section{AGRADECIMENTOS}

À Julienne Mansur da Macedônia Bastos e à Lucimara Jorge Zech, fisioterapeutas do Hospital Pequeno Príncipe, pela ajuda na coleta de dados, e à Karina de Melo pela ajuda com documentos de finalidade ética do comprometimento. Em especial, ao SAME, pela atenção e cuidado durante as coletas.

\section{DECLARAÇÃO DE CONFLITO DE INTERESSES}

Nada a declarar.

\section{FONTES DE FINANCIAMENTO}

Não há.

\section{REFERÊNCIAS}

1. Sweddlow SH, Campo E, Harris LI, et al., editors. WHO Classification of tumours of haematopoietic and lymphoid tissues. 4th. ed. Lyon: Iarc; 2017.

2. BénéMC, NebeT, Bettelheim P, et al. Immunophenotyping of acute leukemia and lymphoproliferative disorders: a consensus proposal of the European LeukemiaNet Work Package 10. Leukemia. 2011;25(4):567-74. doi: https:// doi.org/10.1038/leu.2010.312

3. Zola H, Swart B, Nicholson I, et al. CD molecules 2005: human cell differentiation molecules. Blood. 2005;106(9):3123-6. doi: https://doi.org/10.1182/ blood-2005-03-1338

4. Hutter JJ. Childhood leukemia. Pediatr Rev. 2010;31(6):234-41. doi: https://doi.org/10.1542/ pir.31-6-234

5. Instituto Nacional de Câncer José Alencar Gomes da Silva. Estimativa 2020: incidência de câncer no Brasil [Internet]. Rio de Janeiro: INCA; 2019 [acesso 2021 jan 17]. Disponível em: https://www.inca.gov.br/sites/ufu. sti.inca.local/files//media/document//estimativa-2020incidencia-de-cancer-no-brasil.pdf

6. Jesus CVF, Silva CS, Ferrari YAC, et al. Mortalidade e perfil de crianças vítimas das leucemias agudas no período de 2008 a 2015 no Brasil [Internet]. In: Anais do Congresso Nacional de Enfermagem; 2018 maio 7-11; Aracaju, SE. Aracaju, SE: Universidade Tiradentes; 2018 [acesso 2019 fev 27]. Disponível em: https://eventos.set. edu.br/index.php/conenf/article/view/9327

7. Picon PX. Pediatria: consulta rápida. Porto Alegre: Artmed; 2010.

8. Hazin I, Garcia D, Gomes ERO, et al. Neuropsicologia e oncologia pediátrica: um diálogo em emergência.
Interação Psicol. 2014;18(3):353-3. doi: http://doi. org/10.5380/psi.v18i3.47034

9. Cavalcante MS, Rosa ISS, Torres F. Leucemia linfoide aguda e seus principais conceitos. Rev Cient Facul Edu Meio Ambiente. 2017;8(2):151-64. doi: https://doi. org/10.31072/rcf.v8i2.578

10. Peixoto PPA. Leucemia mielóide crônica: uma revisão de literatura [monografia na Internet]. Natal (RN): Universidade Federal do Rio Grande do Norte; 2017 [acesso 2019 fev 27]. 53 f. Disponível em: http:// monografias.ufrn.br/jspui/handle/123456789/5894

11. Brateibach V, Domenico EBL, Berlezi EM, et al. Sintomas de pacientes em tratamento oncológico. Rev Cien Saude. 2013;6(2):102-9. doi: https://doi. org/10.15448/1983-652x.2013.2.12604

12. Cipolat S, Pereira BB, Ferreira FV. Fisioterapia em pacientes com leucemia: revisão sistemática. Rev Bras Cancerol. 2011;57(2):229-6. doi: https://doi. org/10.32635/2176-9745.RBC.2011v57n2.710

13. Souza JAF, Alves JT, Chamma BM, et al. Atuação da fisioterapia no controle da dor no câncer infantil: uma revisão de literatura. Rev Pesqui Ação [Internet]. 2017 [acesso 2019 fev 27];3(2):73-83. Disponível em: https://revistas.brazcubas.br/index.php/pesquisa/article/ view/319

14. Anders JC, Soler VM, Brandão EM, et al. Aspectos de enfermagem, nutriçáo, fisioterapia e serviço social no transplante de medula óssea. Medicina (Ribeirao Preto). 2000;33(4):463-85. doi: https://doi.org/10.11606/ issn.2176-7262.v33i4p463-485

15. Stucki G, Bickenbach J. Functioning: the third health indicator in the health system and the key indicator for rehabilitation. Eur J Phys Rehabil Med, 2017;53(1):134-8. doi: https://doi.org/10.23736/S1973-9087.17.04565-8

16. Organização Mundial de Saúde. CIF: Classificação Internacional de Funcionalidade, Incapacidade e Saúde. São Paulo: EDUSP; 2019.

17. Castaneda L, Bergmann A, Bahia L. The International Classification of Functioning, Disability and Health: a systematic review of observational studies. Rev Bras Epidemiol. 2014;17(2):437-51. doi: http://doi. org/10.1590/1809-4503201400020012ENG

18. Fontelles MJ, Simôes MG, Farias SH, et al. Metodologia da pesquisa científica: diretrizes para a elaboração de um protocolo de pesquisa. Rev Para Med [Internet]. 2009 [acesso 2019 fev 27];23(3). Disponível em: https://files. cercomp.ufg.br/weby/up/150/o/Anexo_C8_NONAME. pdf

19. Mota RN, Santana AB, Santos CM, et al. A importância da fisioterapia na equipe multidisciplinar oncopediátrica: revisão de literatura. SEMPESq Unit [Internet]. 2014;(16) [acesso 2019 fev 27]. Disponível em: https://eventos.set.edu.br/index.php/conenf/ article/view/9327 
20. Oliveira TH. Perfil clínico epidemiológico de pacientes com leucemia aguda de um hospital público do Distrito Federal. REFACI [Internet]. 2017 [acesso $2019 \mathrm{fev}$ 27];2(3):1-13. Disponível em: http://revista.faciplac.edu. br/index.php/REFACI/article/view/397/145

21. Torres LG. Neutropenia febril e câncer: part I. Revista Onco\& [Internet]. 2011 [acesso 2019 fev 27];1(6):36-9. Disponível em: http://revistaonco.com.br/wp-content/ uploads/2011/05/ONCO_6_NET2.pdf

22. Souza GS, Vasconcelos J, Sá OMS. Repercussão do ciclo quimioterápico no estado nutricional de crianças e adolescentes em Teresina-PI. Rev Interd [Internet]. 2018 [acesso 2019 fev 27];11(3):67-74. Disponível em: https:// dialnet.unirioja.es/servlet/articulo? codigo $=6763749$

23. Beloto NCP. Leucemia linfóide aguda em crianças: revisão histórica, diagnóstico e alternativas de tratamento [monografia na Internet]. Curitiba (PR): Universidade Federal do Paraná; 2010 [acesso 2019 fev 27]. 42 f. Disponível em: https://acervodigital.ufpr.br/ handle/1884/52157?show=full

24. Teston EF, Fukumori EFC, Benedetti GMS, et aL. Sentimentos e dificuldades vivenciadas por pacientes oncológicos ao longo dos itinerários diagnóstico e terapêutico. Esc Anna Nery. 2018;22(4):e20180017. doi: https://doi.org/10.1590/2177-9465-EAN-2018-0017

25. Silva AGS, Moreira HDM, Cavalcante AN. Frequências fenotípicas e alélicas dos sistemas $\mathrm{ABO}$ e $\mathrm{Rh}$ na região centro-norte do estado do Maranhão, Brasil. Pesqui Foco. 2015;20(1):39-52. doi: https://doi.org/10.18817/ pesquisa $\% 20 \mathrm{em} \% 20$ foco.v20i1.783

26. Silva JRO, Ramos ACS, Reis ACS. Prevalência de grupos sanguíneos em um laboratório de Aracaju/SE. SEMPESq Unit [Internet]. 2016;(18) [acesso $2019 \mathrm{fev}$ 27]. Disponível em: https://eventos.set.edu.br/sempesq/ article/view/3734/2570

27. Irmandade da Santa Casa de Misericórdia de São Paulo [Internet]. São Paulo: Irmandade da Santa Casa de Misericórdia de São Paulo; c2018. Tabela de Prevalência de Tipo de Sangue na População; [acesso 2019 fev 27]. Disponível em: https://www.santacasasp.org.br/portal/ site/doe-sangue/pub/4587/web-site-hemocentro-sanguetipo-sanguineo

28. Unidade de Reabilitação do Hospital de Clínicas da Universidade Federal do Triângulo Mineiro. Procedimento operacional padrão: fisioterapia em oncologia pediátrica [Internet]. Brasília, DF: EBSERH; 2016 [acesso 2019 fev 27]. 18 p. Disponível em: http://www2.ebserh.gov.br/documents/147715/0/PO $\mathrm{P}+4+\% 282016 \% 29+$ Fisioterapia $+\mathrm{em}+$ Oncologia $+\mathrm{Pe}$ di\%C3\%A1 trica+3.pdf/7de81653-8afd-42af-937d$9 \mathrm{bd} 7 \mathrm{~b} 689 \mathrm{a} 66 \mathrm{~d}$

29. Marchese VG, Chiarello LA, Lange BJ. Effects of physical therapy intervention for children with acute lymphoblastic leukemia. Pediatr Blood Cancer.
2004;42(2):127-33. doi: https://doi.org/10.1002/ pbc. 10481

30. Almeida EMP, Andrade RG, Cecatto RB, et al. Exercício em pacientes oncológicos: reabilitação. Acta Fisiatr. 2012;19(2):82-9. doi: https://doi.org/10.5935/01047795.20120015

31. Freitas GSS, Gonçalves C, Morais MIDM. A Contribuição da Fisioterapia nos cuidados paliativos em crianças com leucemia. Rev UNIABEU [Internet]. 2016 [acesso $2019 \mathrm{fev}$ 27];9(21):182-92. Disponível em: https://revista.uniabeu. edu.br/index.php/RU/article/viewFile/2161/pdf_315

32. Cruz TC, Nascimento NS, Mattos NDCPM, et al. Avaliação da qualidade de vida de pacientes com leucemia e linfoma hospitalizados. Rev Pesq Fisio. 2018;8(1):94100. doi: http://doi.org/10.17267/2238-2704rpf. v8i1.1789

33. Moraes MLM, Freire M, Silva CM. Avaliação da função pulmonar, força muscular periférica, independência funcional e qualidade de vida em pacientes com leucemia e linfoma durante internamento hospitalar - séries de casos. Rev Cienc Med Biol. 2018;17(2):194-8. doi: http://doi.org/10.9771/cmbio.v17i2.26335

34. Caricchio MBM. Tratar brincando: o lúdico como recurso da fisioterapia pediátrica no Brasil. Rev Eletron Atualiza Saude [Internet]. 2017 [acesso 2019 fev 27];6(6):43-57. Disponível em: http:// atualizarevista.com.br/wp-content/uploads/2017/08/ tratar-brincando-o-1\%C3\%BAdico-como-recurso-dafisioterapia-pedi\%C3\%A1 trica-no-brasil-v-6-n-6.pdf

35. Neves I, Alves L, Gonzalez C. Jogos digitais nas classes hospitalares: desbravando novas interfaces. In: Anais do $11^{\circ}$ Seminário Jogos Eletrônicos, Educação e Comunicação; 2015 jun 01-02; Salvador, BA. Salvador, BA: Grupo de Pesquisa Comunidades Virtuais, Universidade do Estado da Bahia; 2015 [acesso 2019 fev 27]. Disponível em: https://www.revistas.uneb.br/index. $\mathrm{php/sjec/article/view/1243}$

36. Burdos DBL. Fisioterapia paliativa aplicada ao paciente oncológico terminal. Ens Cienc. 2017;21(2):11722. doi: https://doi.org/10.17921/14156938.2017v21n2p117-122

37. Conselho Federal de Fisioterapia e Terapia Ocupacional (BR). Resolução no 414, de 23 de maio de 2012. Dispóe sobre a obrigatoriedade do registro em prontuário pelo fisioterapeuta, da guarda e do seu descarte e dá outras providências [Internet]. Diário Oficial da União, Brasília, DF; 2012 maio 23. Seção 1. [acesso 2019 fev 27]. Disponível em: https://www.coffito.gov.br/nsite/?p=1727

38. Conselho Federal de Fisioterapia e Terapia Ocupacional (BR). Resolução no 415, de 19 de maio de 2012. Dispóe sobre a obrigatoriedade do registro em prontuário pelo terapeuta ocupacional, da guarda e do seu descarte e dá outras providências. [Internet]. Diário Oficial da União, Brasília, DF; 2012 maio 23. Seção 1. [acesso 
2019 fev 27]. Disponível em: https://www.coffito.gov. $\mathrm{br} / \mathrm{nsite} / \mathrm{p}=3178$

39. Teixeira ALG, Minetto AI, Longen WC, et al. Revisão nos registros dos prontuários médico no setor de Fisioterapia das clínicas integradas UNESC. Inova Saude. 2017;6(2):98-114. doi: http://doi.org/10.18616/ is.v6i2.2485

40. Araujo LB, Israel VL, organizadores. Desenvolvimento da criança: família, escola e saúde [Internet]. Curitiba, PR: Omnipaz; 2017 [acesso 2019 fev 27]. 186 p. Disponível em: http://omnipax.com.br/livros/2017/DCFES/dcfeslivro.pdf

41. Ruaro JA, Ruaro MB, Souza DE, et al. Panorama e perfil da utilização da CIF no Brasil: uma década de história. Rev Bras Fisioter. 2012;16(6):454-62. doi: https://doi. org/10.1590/S1413-35552012005000063

42. Batista AF, Lopes F, Carvalheiro I, et al. Perspetiva do fisioterapeuta sobre o core set da classificação internacional de funcionalidade, incapacidade e saúde da diabetes mellitus [monografia na Internet]. Portugal: Instituto Politécnico de Leiria, Escola Superior de Saúde; 2016 [acesso 2019 fev 27]. 305 p. Disponível em: http:// hdl.handle.net/10400.8/1999

43. Araújo ES, Buchalla CM. Utilização da CIF em Fisioterapia do trabalho: uma contribuição para coleta de dados sobre funcionalidade. Acta Fisiátrica. 2013;20(1):1-7. doi: https://doi.org/10.5935/01047795.20130001 